\title{
Detection of milk powder and caseinates in Halloumi cheese
}

\author{
L. Pellegrino, ${ }^{* 1}$ S. Cattaneo, ${ }^{*}$ F. Masotti, ${ }^{*}$ and G. Psathas $\dagger$ \\ *Dipartimento di Scienze e Tecnologie Alimentari e Microbiologiche, Università degli Studi di Milano, I-20133 Milano, Italy \\ †The Cyprus Milk Industry Organisation, Nicosia, CY-1900 Cyprus
}

\section{ABSTRACT}

Halloumi cheese is traditionally manufactured from fresh milk. Nevertheless, dried dairy ingredients are sometimes illegally added to increase cheese yield. Lysinoalanine and furosine are newly formed molecules generated by heating and drying milk protein components. The levels of these molecular markers in the finished Halloumi have been investigated to verify their suitability to reveal the addition of skim milk powder and calcium caseinate to cheese milk. Because of the severe heating conditions applied in curd cooking, genuine Halloumi cheeses $(\mathrm{n}=35)$, representative of the Cyprus production, were characterized by levels of lysinoalanine (mean value $=8.1 \mathrm{mg} / 100 \mathrm{~g}$ of protein) and furosine (mean value $=123 \mathrm{mg} / 100 \mathrm{~g}$ of protein) unusual for natural cheeses. Despite the variability of the values, a good correlation between the 2 parameters $(\mathrm{R}$ $=0.975$ ) has been found in all cheeses, considering both the fresh and mature cheeses as well as those obtained from curd submitted to a prolonged cooking following a traditional practice adopted by a very small number of manufacturers. Experimental cheeses made by adding as low as $5 \%$ of skim milk powder, or calcium caseinate, or both, to cheese milk fell outside the prediction limits at \pm 2 standard deviation of the above-reported correlation regardless of curd cooking conditions or ripening length. This correlation may be adopted as a reliable index of Halloumi cheese genuineness.

Key words: Halloumi cheese, cheese genuineness, furosine, lysinoalanine

\section{INTRODUCTION}

A variety of dried dairy ingredients have been proposed for use in cheesemaking with the intent of both standardizing milk composition and increasing cheese yield (Yun et al., 1998; Guinee et al., 2006; Kelly, 2008). The composition of industrially available milk protein powders varies widely depending on the liquid

Received November 19, 2009.

Accepted April 4, 2010.

${ }^{1}$ Corresponding author: luisa.pellegrino@unimi.it source product and the processing steps involved in their manufacture. Hence, their suitability as cheese ingredients varies as well. Nevertheless, individual cheese standards in several countries still prohibit the use of these ingredients in many types of cheese.

Literature reports that furosine (FUR) and lysinoalanine (LAL) are molecular markers that allow milk powder and casein or caseinates, respectively, to be traced in Mozzarella cheese (Resmini and Pellegrino, 1991; Pellegrino et al., 1996; Calabrese et al., 2009). In fact, dedicated research (Resmini et al., 2003) demonstrated that genuine Mozzarella, including all types of fresh pasta filata cheese, has FUR levels up to 8 to $10 \mathrm{mg} / 100 \mathrm{~g}$ of protein and LAL levels lower than $0.2 \mathrm{mg} / 100 \mathrm{~g}$ of protein. For this type of cheese the Italian legislation (Italian Legislation, 2000) provides a maximum limit of FUR of $12 \mathrm{mg} / 100 \mathrm{~g}$ of protein to prevent use of milk powder in cheesemaking. With the same intent, a limit of $10 \mathrm{mg} / 100 \mathrm{~g}$ of protein has been established for FUR in Mozzarella cheese when labeled as Traditional Specialty Guaranteed within the European Union (European Commission, 1998). Furosine is accepted worldwide as an index of the early stage of Maillard reaction in food products. It can be detected at trace levels $(4-5 \mathrm{mg} / 100 \mathrm{~g}$ of protein) in raw milk and increases by 1 to $2 \mathrm{mg} / 100 \mathrm{~g}$ protein after HTST pasteurization treatments, leaving the peroxidase positive. In milk powders, FUR levels are rated from 80 to $300 \mathrm{mg}$, reaching up to 600 to $700 \mathrm{mg} / 100 \mathrm{~g}$ of protein after prolonged storage (Resmini and Pellegrino, 1994; Van Renterghem and De Block, 1996) as the Maillard reaction sharply increases in dried and semidried foods (Labuza and Saltmarch, 1981). Lysinoalanine is the most studied protein cross-link formed upon heat treatment (Friedman, 1999). Specific AA undergo preliminary $\beta$-elimination reactions with the formation of an unstable intermediate (dehydroalanine) that promptly reacts with lysine residues, leading to the formation of LAL (Cuq and Cheftel, 1985). Its formation is enhanced by alkaline $\mathrm{pH}$ and absence of reducing sugars. Therefore, very high levels of LAL (up to $50 \mathrm{mg} / 100 \mathrm{~g}$ of protein) characterize industrial casein and caseinates (Resmini et al., 2003). Both LAL and FUR formation involves lysine residues in protein so that these 2 reac- 
tions are in competition to some extent. In presence of lactose (like in milk powder), the Maillard reaction takes place extensively and FUR represents the main reaction product. On the contrary, when lactose is mostly removed during manufacturing (casein and caseinates) the Maillard reaction is largely suppressed and LAL becomes the characterizing compound. In principle, detection of use of both milk powder and caseinate in cheesemaking can be achieved in every type of cheese by the same approach as for Mozzarella cheese depending on the manufacturing process, type, and amount of added ingredient.

Halloumi is a rindless semihard cheese that is traditionally made in Cyprus using sheep or goat milk or a mixture thereof, with or without cow milk. According to the traditional cheesemaking process (Papademas and Robinson, 1998), milk is coagulated with rennet at $33^{\circ} \mathrm{C}$ in about 40 to $60 \mathrm{~min}$, the curd is extracted, and the whey is heated to 80 to $90^{\circ} \mathrm{C}$ for $30 \mathrm{~min}$ to coagulate the whey proteins. The curd is cut to $1 \mathrm{~cm}^{3}$ and then pressed and shaped. Blocks of pressed curd $(10 \times 15 \times 3 \mathrm{~cm})$ are placed in hot deproteinized whey $\left(94-96^{\circ} \mathrm{C}\right)$ for at least $30 \mathrm{~min}$. After drainage and cooling, the cheese is dry salted and stored in brine or shrink wrapped. Only few limits in the manufacturing conditions (namely milk pasteurization and curd cooking) are established by regulations (Cyprus Standard, 1985). Therefore, each cheesemaker uses unique empirical conditions of processing and product characteristics may vary from dairy to dairy throughout the island.

In recent years the use of cow milk in Halloumi cheese manufacturing has spread, mainly because of its year-round availability and lower cost. To increase cheese yield, the use of milk powder or other dried dairy ingredients may be envisaged as an advantageous solution, especially for small dairies where the adoption of milk UF is technologically and economically unrealistic at present.

The main technological aspects related to use of milk powders in the production of Halloumi cheese have been discussed by some authors (Lelievre et al., 1991; Papadema and Robinson, 1998). However, considering the growing popularity of Halloumi, its registration procedure as Protected Designation of Origin cheese has started over on 2006 with the aim of protecting its identity. According to product specification (Cyprus Standard, 1985), the use of dairy ingredients other than fresh milk cannot be accepted.

This research aimed to evaluate the possibility of tracing milk powder and caseinate in traditional Halloumi cheese, as produced in Cyprus, on the basis of its levels of FUR and LAL. As far as we know, no attempt has been made until now in this regard. Because Halloumi is manufactured mainly near small artisan dair- ies under rather different conditions of processing, the most relevant part of the work has been dedicated to evaluating the actual variability of FUR and LAL levels in the genuine cheeses to assess the feasibility of the proposed approach. The study of influence of making Halloumi from fortified milk on its physical and sensory properties was not within the goals of this work.

\section{MATERIALS AND METHODS}

\section{Cheese Samples}

All the cheese samples were manufactured at different cheese factories under the supervision of The Cyprus Milk Industry Organisation (Nicosia, Cyprus ) to secure the pureness of milk and to record details of processing conditions. From each cheesemaking, parameters were recorded regarding time and temperature of milk pasteurization and curd cooking, temperature and $\mathrm{pH}$ of cooking whey, final temperature, and $\mathrm{pH}$ inside the core of cheese pieces.

A total of 62 Halloumi cheese samples were analyzed: genuine cheeses $(n=35)$ manufactured using traditional technology and differing for some technological characteristics as reported in Table 1; experimental cheeses $[\mathrm{n}=4$; control cheese, cheese from milk added with either $5 \%$ skim milk powder (SMP), or $5 \%$ calcium caseinate $(\mathbf{C a C N})$, or $2.5 \% \mathrm{SMP}+2.5 \% \mathrm{CaCN}$ submitted to ordinary (50 min) cooking process]; experimental cheeses $(n=2)$ (control cheese, cheese from milk added with $5 \%$ SMP) submitted to prolonged (80 min) cooking process; cheeses $(n=5)$ manufactured in a dairy factory on 5 different days and analyzed fresh $(24 \mathrm{~h})$ and after maturation (at $4^{\circ} \mathrm{C}$ for $40 \mathrm{~d}$ ); cheeses $(\mathrm{n}=10)$ laboratory submitted to additional heating under whey at $95^{\circ} \mathrm{C}$ and sampled every $2 \mathrm{~h}$ up to $8 \mathrm{~h}$; and commercial Halloumi cheeses $(\mathrm{n}=6)$ purchased at the European market. All cheeses (100-150 g each) were individually packed in plastic bags, sealed, and shipped under refrigerated conditions to our laboratory for analyses. Batches of SMP and $\mathrm{CaCN}$ for manufacturing experimental cheeses were purchased from Mlekovita (Wysokie Mazowieckje, Poland) and DMV International (Vaghel, the Netherlands), respectively.

\section{$\beta-C N$ Glycation}

Besides FUR, Maillard reaction can be monitored also by measuring lactosylation of proteins by capillary electrophoresis (Otte et al., 1998). The formation of lactosylated casein in Halloumi cheese was tested by capillary zone electrophoresis (CZE). As a reference material, lactosylated $\beta-\mathrm{CN}$ was prepared as follows. A water solution containing $25 \mathrm{mg} / \mathrm{mL}$ of $\beta-\mathrm{CN}$ (Sigma 
Table 1. Levels (mg/100 g of protein) of furosine (FUR) and lysinoalanine (LAL) in traditional Halloumi cheeses differing for some technological characteristics

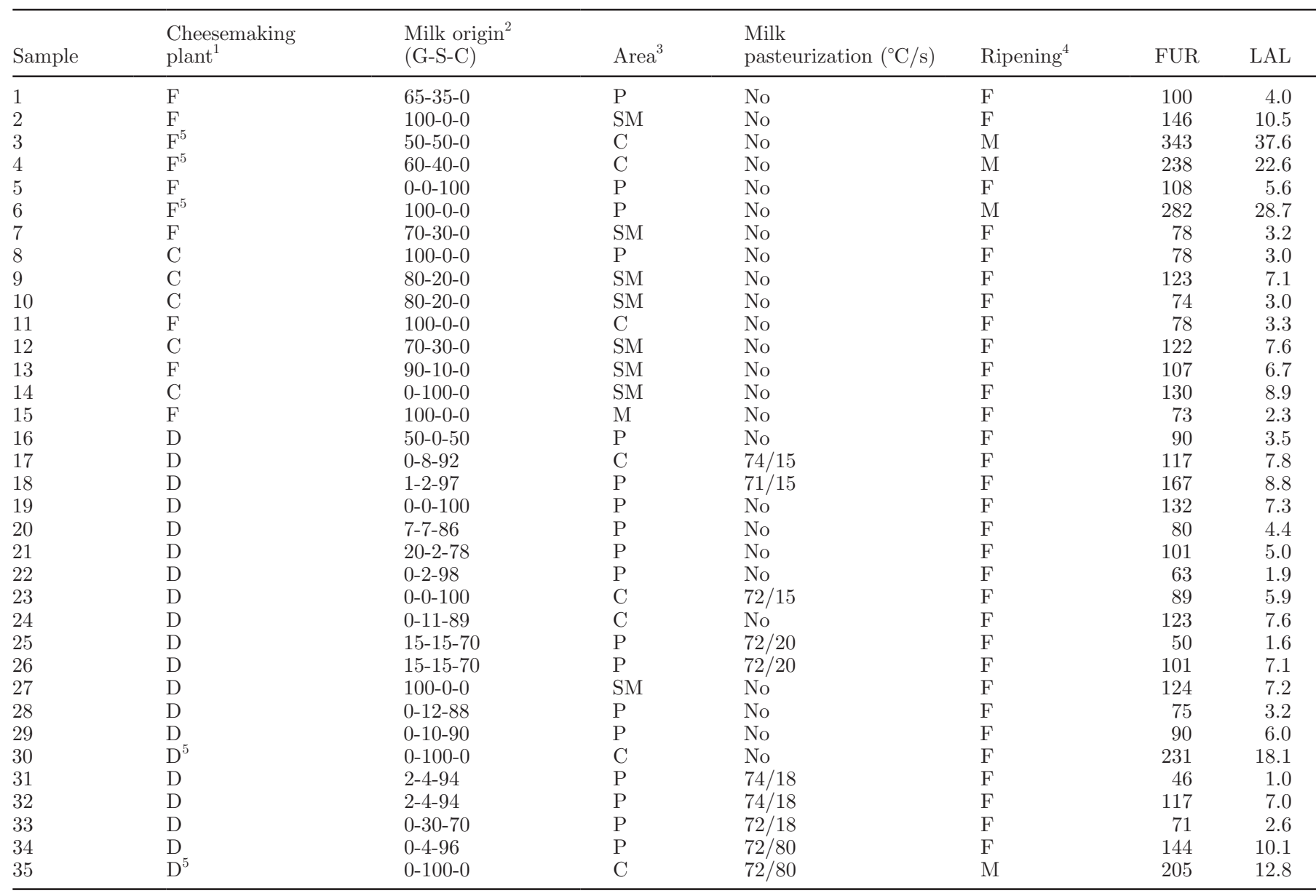

${ }^{1} \mathrm{~F}$ : small farmhouse; C: cottage; D: dairy.

${ }^{2} \mathrm{G}-\mathrm{S}-\mathrm{C}$ : relative percentage (vol/vol) of goat, sheep, and cow milk.

${ }^{3} \mathrm{P}$ : plain; C: coastal; SM: semimountainous; M: mountainous.

${ }^{4} \mathrm{~F}$ : fresh cheese (24 h old); M: mature cheese.

${ }^{5}$ Prolonged cooking of the curd.

Chemical Co., St. Louis, MO) and $10 \mathrm{mg} / \mathrm{mL}$ of lactose (Sigma) was kept at $90^{\circ} \mathrm{C}$ for $45 \mathrm{~min}$. The reacted mixture was diluted (1:2) with sample buffer as described by Recio et al. (1997) for CZE. After filtration on a $0.22-\mu \mathrm{m}$ disposable filter, glycated $\beta-\mathrm{CN}$ was analyzed by CZE.

\section{Analytical Methods}

The level of FUR was determined by HPLC according to the Standard ISO18329 IDF193 (ISO-IDF, 2004). A 150-mg aliquot of cheese was added with 8 $\mathrm{mL}$ of $8 \mathrm{~N} \mathrm{HCl}$, hydrolyzed at $110^{\circ} \mathrm{C}$ for $23 \mathrm{~h}$, and 0.5 $\mathrm{mL}$ of hydrolyzate purified with solid phase extraction on a 500-mg C18 cartridge (WAT020805, Millipore, Milford, MA). Ion-pair reverse phase-HPLC was per- formed on a C8 column (furosine-dedicated column, Alltech, Lokeren, Belgium). An Alliance 2695 HPLC system (Waters, Milford, MA) equipped with a Waters $486 \mathrm{UV}$ detector was used. Absorbance at $280 \mathrm{~nm}$ was recorded and reprocessed using the Millennium software package (Waters, Milford, MA). The level of LAL was determined according to Pellegrino et al. (1996) using a C18 column $(2.1 \times 200 \mathrm{~mm}, 5 \mu \mathrm{m}$; Hypersil AA-ODS, Agilent Technologies, Waldbronn, Germany) with the same HPLC equipment and signal reprocessing software. The fluorescence detection (excitation at $260 \mathrm{~nm}$, emission at $310 \mathrm{~nm}$ ) was performed using a VWR L2485 detector (West Chester, PA). One hundred microliters of hydrolyzate, obtained as described for FUR determination, were vacuum dried, solubilized with $200 \mu \mathrm{L}$ of $0.4 M$ boric acid (adjusted to $\mathrm{pH} 12.00$ 
using $12 M \mathrm{NaOH}$ ) and $200 \mu \mathrm{L}$ of water, and submitted to derivatization by adding $400 \mu \mathrm{L}$ of 9-fluorenylmethyl chloroformate solution $(0.2 \mathrm{mg} / \mathrm{mL}$ of acetonitrile; ACN). The derivatized sample underwent solid phase extraction purification on a 500-mg amino cartridge (Bakerbond, Deventer, the Netherlands) activated with $10 \mathrm{~mL}$ of $\mathrm{ACN}$ and washed with a mixture (1:3, vol/ vol) of ACN and 0.1 $M$ boric acid solution adjusted to $\mathrm{pH} 7.20$ using $6 \mathrm{M} \mathrm{NaOH}$. Elution was performed using a mixture $(1: 1, \mathrm{vol} / \mathrm{vol})$ of $\mathrm{ACN}$ and $0.2 M$ boric acid solution adjusted to $\mathrm{pH} 9.00$ using $12 \mathrm{M} \mathrm{NaOH}$. Levels of FUR and LAL were expressed on protein basis. Protein content was determined on $3 \mathrm{~mL}$ of acid hydrolyzate according to Kjeldahl method (ISO-IDF, 2008).

Conditions for CZE of glycated $\beta$-CN were those described by Recio et al. (1997). Analyses were carried out on a Beckman $\mathrm{P} / \mathrm{ACE}$ system MDQ (Beckman Instruments Inc., Fullerton, CA). Casein fractions were identified by comparison with literature data (Masotti et al., 2010). All reagents were of recognized analytical grade.

\section{Statistical Analyses}

All FUR and LAL analyses were carried out in duplicate and mean values are reported. In all cases the precision of the determinations complied with those specified for the respective analytical methods. Statistical evaluation of data was carried out using the RS/1 software suite (Domain Solutions Corp., Cambridge, MA).

\section{RESULTS AND DISCUSSION}

\section{Natural Levels of FUR and LAL in Traditional Halloumi Cheese}

The most characteristic technological step in Halloumi cheesemaking is the cooking of the pressed curd in the hot $\left(80-95^{\circ} \mathrm{C}\right)$ deproteinized whey for 30 to $60 \mathrm{~min}$ (Alichanidis and Polychroniadou, 2008). Therefore, the presence of both FUR and LAL at high levels (mean values: 123 and $8.1 \mathrm{mg} / 100 \mathrm{~g}$ of protein, respectively) characterizes the genuine Halloumi cheese (Table 1). Such levels are not found in other types of cheese, with the exception of processed cheeses (Resmini and Pellegrino, 1991; Pellegrino et al., 1997; Villamiel et al., 2000), proving that the manufacturing conditions of Halloumi include at least 1 overheating step. As a term of reference, FUR can go up to 180 to $200 \mathrm{mg} / 100 \mathrm{~g}$ of protein and LAL up to 9 to $10 \mathrm{mg} / 100 \mathrm{~g}$ of protein in freshly produced UHT milk (Cattaneo et al., 2008). Data of both FUR and LAL show a great variability (expressed as CV values reported in Table 2) irrespec-
Table 2. Minimum, maximum, mean, and CV values of furosine (FUR) and lysinoalanine (LAL) levels $(\mathrm{mg} / 100 \mathrm{~g}$ of protein) calculated either for all of the Halloumi cheese samples or for the fresh ( $24 \mathrm{~h}$ old) cheeses only

\begin{tabular}{lcc}
\hline Item & FUR & LAL \\
\hline All samples $(\mathrm{n}=35)$ & & \\
Minimum & 52 & 2.1 \\
Maximum & 343 & 38 \\
Mean & 123 & 8.1 \\
CV & 53 & 9.6 \\
Fresh cheeses only $(\mathrm{n}=31)$ & & \\
Minimum & 52 & 2.1 \\
Maximum & 213 & 17 \\
Mean & 104 & 5.8 \\
CV & 36 & 5.9 \\
\hline
\end{tabular}

tive of ripening period. Actually, the sample set includes only 4 mature cheeses, which, therefore, represent outliers. In fact, when only fresh cheeses are considered, the variability (CV value) is lower. When the 31 samples of fresh Halloumi cheese analyzed in this project are considered, where all main sources of variability are included, FUR varies by a factor of approximately 4 and LAL by a factor of 8 . This depends mainly on the wide range of variation of in-vat processing conditions adopted at the different dairies considered in this research, as summarized in Table 3. In contrast, the effect of milk pasteurization can be disregarded because the time and temperature conditions used did not promote LAL formation and the increase of FUR in cheese milk was on the order of 2 to $3 \mathrm{mg}$ (data not shown). Despite the relevant variations of scalding and cooking conditions of the curd, a strict correlation $(\mathrm{R}=0.975)$ was found to exist between FUR and LAL levels for all the cheeses, as shown in Figure 1. It is noteworthy that all of the samples, both fresh and mature, fell within the prediction limits at \pm 2 standard deviation irrespective of the production area, type of cheese milk, and processing conditions adopted.

In 3 cases, 2 samples were collected from the same manufacturer to compare the data obtained by adopting different processing conditions at the same cheese plant. Data points for dairies C, P, and A are evidenced in Figure 2. Both $\mathrm{C}$ and $\mathrm{P}$ are large dairies. Samples $\mathrm{P}-1$ and $\mathrm{C}-1$ were obtained from the first batch in the morning and samples P-2 and C-2 were obtained from the last batch (the sixth and eighth batches, respectively) of the same day. The curd cooking process was almost the same for morning and afternoon samples for dairy $\mathrm{P}\left(70-80 \mathrm{~min}\right.$ at $\left.89-90^{\circ} \mathrm{C}\right)$, whereas for dairy $\mathrm{C}$ it was faster in the first batch than in the last one $(30$ and $50 \mathrm{~min}$, respectively, at $89-90^{\circ} \mathrm{C}$ ). The prolonged use (i.e., 5-6 h) of the same whey for cooking 7 to 8 subsequent batches of curd at $90^{\circ} \mathrm{C}$ might explain the different positioning of data points P-2 and C-2 with 


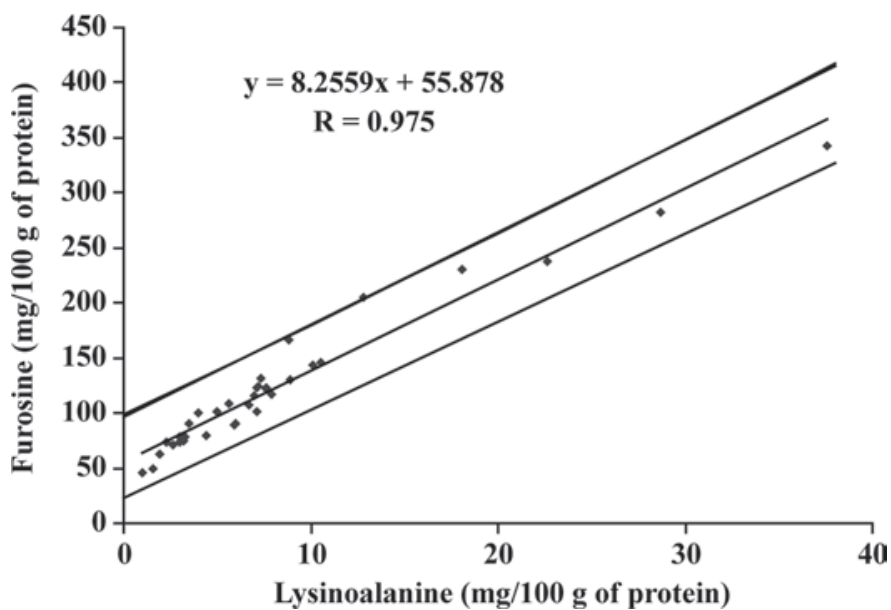

Figure 1. Correlation between lysinoalanine and furosine values in 35 samples of traditional Halloumi cheese. Prediction limits at \pm 2 $\mathrm{SD}$ are shown.

respect to data points $\mathrm{P}-1$ and $\mathrm{C}-1$ in the graph. The relative positioning of data points of the 2 dairies does not seem to be significant. The main difference between the cheesemaking processes in use at the 2 dairies regards the scalding conditions adopted during in-vat processing, which were significantly milder for dairy $\mathrm{C}$ $\left(36^{\circ} \mathrm{C}\right.$ for $\left.15 \mathrm{~min}\right)$ than for dairy $\mathrm{P}\left(42^{\circ} \mathrm{C}\right.$ for $\left.50 \mathrm{~min}\right)$. Furthermore, the duration of the whole cheesemaking (from rennet addition to end of curd cooking) was shorter (150 min) for both C-1 and C-2 than for P-1 and P-2 (210 and $270 \mathrm{~min}$, respectively). These differences in cheesemaking conditions only slightly influenced the correlation between FUR and LAL and were reflected mainly on the body texture of the cheese produced by these 2 plants (data not shown). As a general remark, time and temperature conditions at dairy $\mathrm{C}$ seemed more repeatable than those at dairy $\mathrm{P}$, whereas cheese characteristics, markedly the $\mathrm{pH}$ value, showed the opposite. In particular, C-1 showed an inelastic structure and $\mathrm{pH} 6.32$ whereas $\mathrm{C}-2$ was elastic and had a $\mathrm{pH}$ of 6.02. This situation, however, could be limited to the cheesemaking trials recorded for this project and does not necessarily represent the norm. Dairy A follows an older style process, still in use in a limited area of the island, without curd pressing but with a prolonged cooking (65 min) in hot whey (up to $97^{\circ} \mathrm{C}$ ). The inner

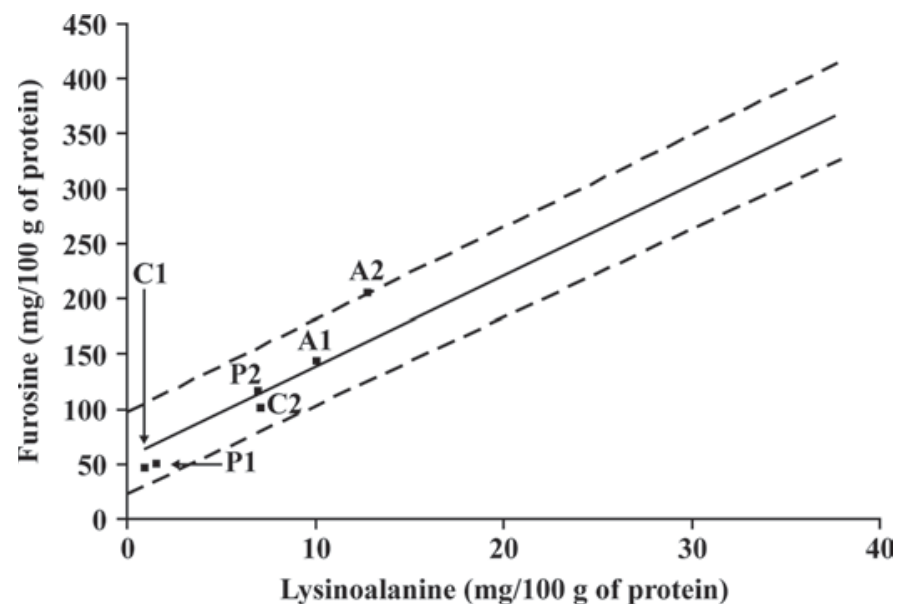

Figure 2. Positioning of traditional Halloumi cheeses from 3 different dairies $(\mathrm{A}, \mathrm{C}, \mathrm{P})$ in the correlation between lysinoalanine and furosine of Figure 1.

temperature of the curd reached $93.3^{\circ} \mathrm{C}$ and the cheese color was light yellow.

To clarify the effect of the prolonged cooking of curd on the FUR:LAL ratio, 2 sets of Halloumi cheese were submitted to additional heat treatment under whey at $95^{\circ} \mathrm{C}$ for $8 \mathrm{~h}$. Cheeses were sampled for LAL and FUR determination every $2 \mathrm{~h}$. As shown in Figure 3, the 2-h heat treatment made the cheeses move along the correlation line calculated for traditional Halloumi, allowing these samples to still fall in the area delimited by the prediction limits at \pm 2 standard deviation. When the cooking process was prolonged for 4 to $8 \mathrm{~h}$, the samples moved out the area of traditional Halloumi, decreasing below the -2 standard deviation limit. In fact, under these conditions FUR degradation took place extensively whereas LAL formation sharply increased, probably because of the high $\mathrm{pH}$ value. Because reaction kinetics of LAL formation are not known, LAL behavior could not be interpreted. However, the cooking conditions applied in this trial were intentionally forced, leading to production of unacceptable brownish-red cheeses.

\section{Effect of Cheese Maturation}

It is well known that storage conditions, markedly temperature, affect both the Maillard and $\beta$-elimination

Table 3. Minimum and maximum values of temperature $\left(\mathrm{T},{ }^{\circ} \mathrm{C}\right)$ and time $(\mathrm{t}, \mathrm{min})$ adopted in the main steps of Halloumi cheesemaking at the industrial dairies tested in the project

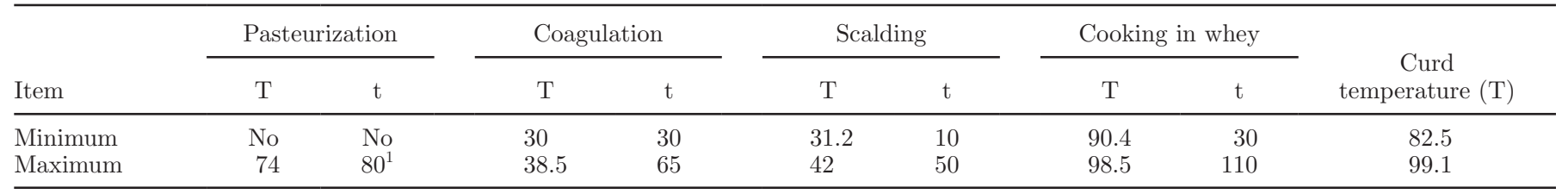

\footnotetext{
${ }^{1}$ Seconds.
} 


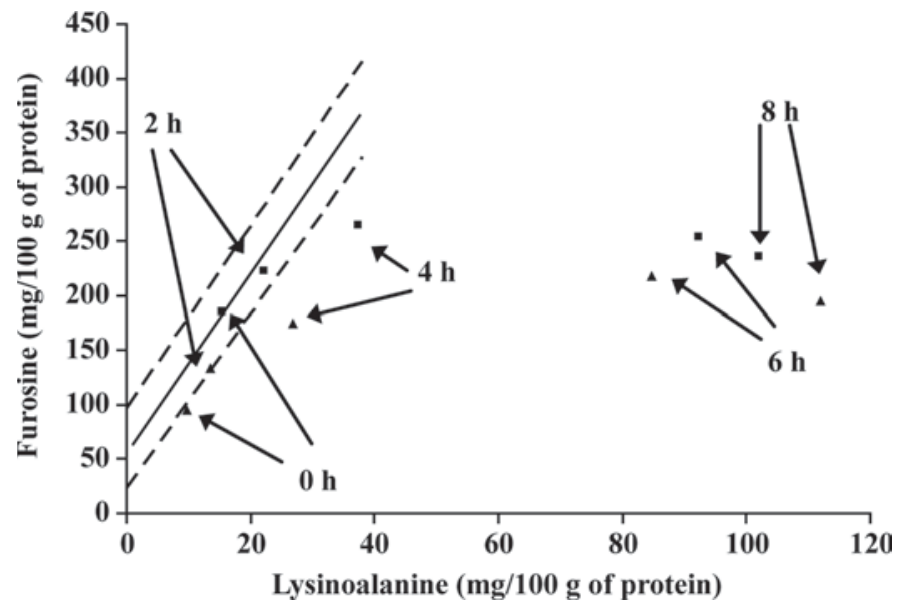

Figure 3. Correlation between lysinoalanine and furosine values in Halloumi cheese manufactured with bovine $(\boldsymbol{\Delta})$ or goat $(\boldsymbol{\square})$ milk and submitted to heat treatment at $95^{\circ} \mathrm{C}$ for 0 to $8 \mathrm{~h}$. Correlation line and prediction limits at $\pm 2 \mathrm{SD}$ as in Figure 1 .

reactions in several dairy products (Van Renterghem and De Block, 1996; Cattaneo et al., 2008). Although Halloumi, either fresh or mature, is usually packed under vacuum and stored at 2 to $4^{\circ} \mathrm{C}$ (Papademas, 1993), the effect of maturation time on the final levels of FUR and LAL in this type of cheese has been evaluated, considering the high levels of these 2 molecules in the freshly produced cheese. Because of exposure to very high temperatures during manufacturing, both enzymes and microorganisms are extensively inactivated in Halloumi cheese. Raphaelides et al. (2006) showed that weakening of Halloumi cheese structure occurring during ripening mainly depends on physicochemical factors (e.g., solubilization of calcium ions bound to casein) favored by the high $\mathrm{pH}$ values. The electropherograms of Halloumi cheese at different ripening stages (Figure 4) confirm that proteolytic degradation of casein fractions is very limited even after $40 \mathrm{~d}$ of maturation. Furthermore, these patterns show that the lactosylated forms of caseins are already evident in the fresh cheese, thus confirming that the Maillard reaction is mainly induced by the cheesemaking conditions. In fact, we verified that the peak area ratios glycated:native form of $\beta-\mathrm{CN}$ A1 and A2 increased by only $8 \%$ upon maturation. To confirm further formation of the marker molecules during maturation, a set of cheeses were analyzed fresh and after storage in brine at $13^{\circ} \mathrm{C}$ for $40 \mathrm{~d}$. Levels of FUR and LAL showed an average increase of 15 and $41 \%$, respectively, after maturation, confirming the progress of the 2 reactions at relatively low temperature and sensitivity of LAL as marker of storage conditions of dairy products having near neutral $\mathrm{pH}$ value. Despite this, cheese ripening gave rise to only slight modifications of the LAL:FUR ratio, so that the mature Hal- loumi samples moved along the correlation line and fell in the area delimited by the prediction limits at \pm 2 standard deviation (data not shown). Therefore, when these samples were included in the model calculation, both the slope and the intercept of the correlation line did not change, thus confirming the reliability of the proposed model.

\section{Levels of FUR and LAL in Experimental Samples of Halloumi Cheese Produced with Milk Powder, or Caseinate, or Both, Added to Cheese Milk}

On the basis of the results obtained in the preliminary study and taking the above-reported observations into consideration, it can be reasonably stated that the addition of either SMP or CaCN to Halloumi cheese should increase the level of FUR or LAL accordingly. Meanwhile, fixing a maximum level for both the markers does not allow the revelation of this manipulation in those cheeses where the initial levels are low. Therefore, the irregular cheeses could be identified by adopting the appropriate prediction limits (i.e., $\pm 2 \mathrm{SD}$ ) of the correlation line between FUR and LAL reported in Figure 1. A first attempt to demonstrate the feasibility of this approach has been done on cheese samples produced with known amounts of SMP and CaCN.

The batches of commercial SMP and $\mathrm{CaCN}$ were tested for FUR and LAL levels first. As expected from the literature (Resmini and Pellegrino, 1994; Van Renterghem and De Block, 1996; Friedman, 1999; Resmini et al., 2003), the former showed a high level of FUR $(193 \mathrm{mg} / 100 \mathrm{~g}$ of protein) with no LAL and the latter showed the opposite (i.e., an LAL level of $200 \mathrm{mg} / \mathrm{kg}$ of protein with $34 \mathrm{mg}$ of FUR only). These 2 powders were used to produce experimental cheeses, as described in the Materials and Methods section. The levels of SMP and CaCN added to cheese milk were chosen to reliably detect the effect of the added ingredient on the levels of FUR and LAL from one side, and to obtain finished cheeses with acceptable sensory properties, and therefore represent possible target levels of fortification for cheesemakers, on the other side. However, the latter result was only partly achieved. The addition of $5 \%$ SMP to cheese milk caused the levels of FUR and LAL of samples A and B (Figure 5) to not fit the correlation line between the 2 indices and to fall out the prediction limit at +2 standard deviation level. This shifting was more marked when a prolonged cooking of the curd was applied (sample B). The addition of $5 \% \mathrm{CaCN}$ caused the cheese (sample $\mathrm{C}$ ) to move even farther away from the prediction limits. This effect can be partly explained by the fact that, contrary to SMP, the whole protein fraction of $\mathrm{CaCN}$ is retained in the curd. In addition, as we have already demonstrated, 


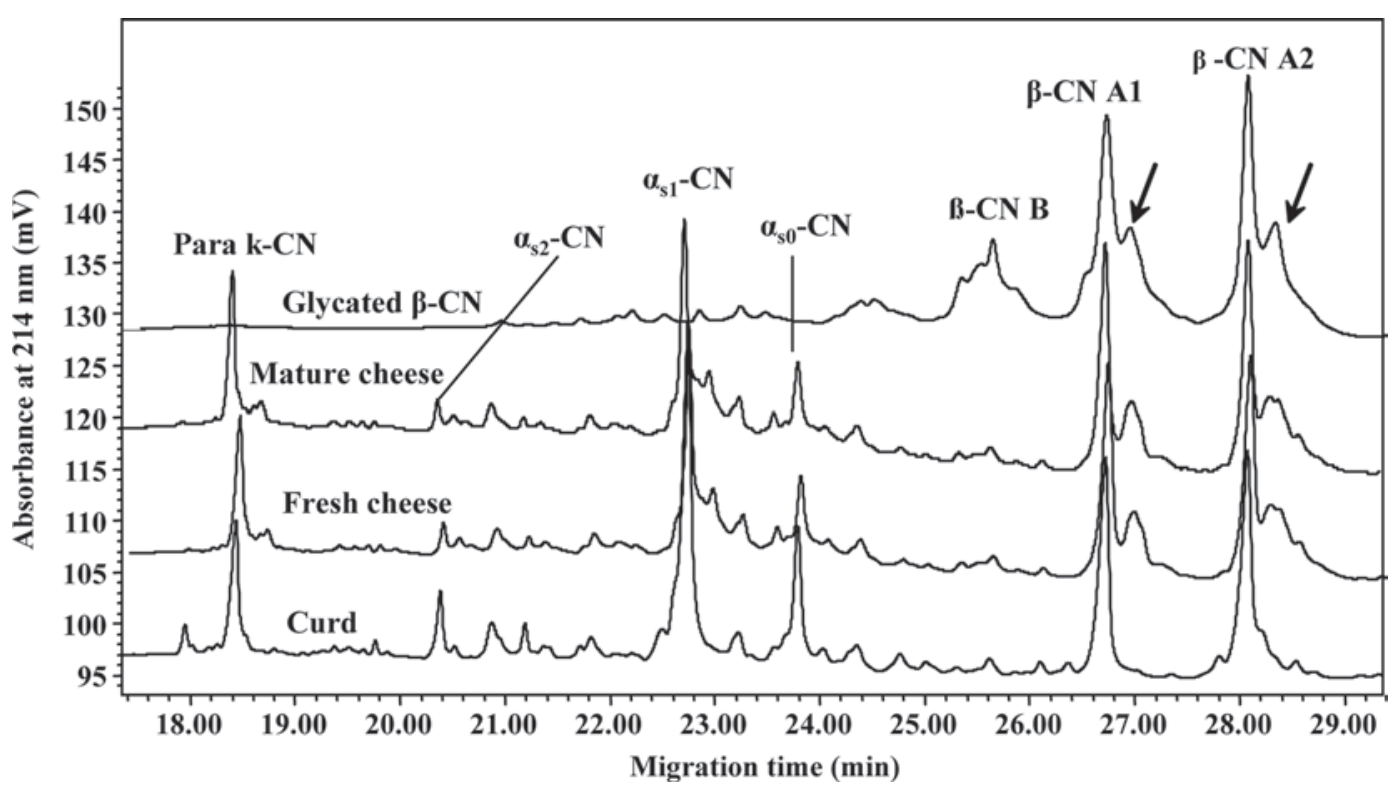

Figure 4. Electropherograms of curd, fresh (24 h old) and mature (40 d old) Halloumi cheese, and $\beta$-CN dispersion heated in presence of lactose. Arrow indicates glycated forms of casein fractions.

the conditions of cheesemaking process itself seem to promote the formation of LAL much more than that of FUR. It must be emphasized that, in this trial, the adoption of a prolonged cooking led to a curd with unacceptable textural characteristics (sticking and very elastic) and a cheese could not be obtained. Therefore, the sample was not analyzed. When $5 \%$ of the mixture of the 2 ingredients (i.e., 2.5\% SMP and $2.5 \% \mathrm{CaCN}$ ) was added to cheese milk, the finished cheese (sample D of Figure 5), submitted to an ordinary cooking step, fell out the prediction limit at -2 standard deviation level. Also in this case, a prolonged cooking of the curd could not be performed for the reason of similar textural characteristics. Problems that arise in making Halloumi from milk added with $\mathrm{CaCN}$ in combination with a prolonged cooking of the curd are likely attributable to the increased content of casein with respect to fat, and addition of cream would highly improve the texture of the finished cheese. Fat homogenization is also reported as a useful tool for overcoming these problems in Halloumi cheese made from recombined milk (Lelievre et al., 1990). However, the optimization of technological conditions for making Halloumi from milk fortified with dried dairy ingredients was not within the aims of this work.

\section{CONCLUSIONS}

This study has shown for the first time that the levels of FUR and LAL in genuine Halloumi cheese can be very high, mainly because of heating conditions adopted during curd cooking. Despite variability of milk origin, type of plant, cheesemaking conditions, and length of ripening, the levels of the 2 marker molecules prove to be strictly correlated in the finished cheese. On this basis, the determination of the ratio between FUR and LAL could be a useful tool for evaluating the genuineness of Halloumi cheese in respect to the use of cheese milk fortified with dried dairy products. Taking into account that the levels of the 2 molecular markers may vary widely in commercial dried ingredients, a minimum detection limit cannot be established without

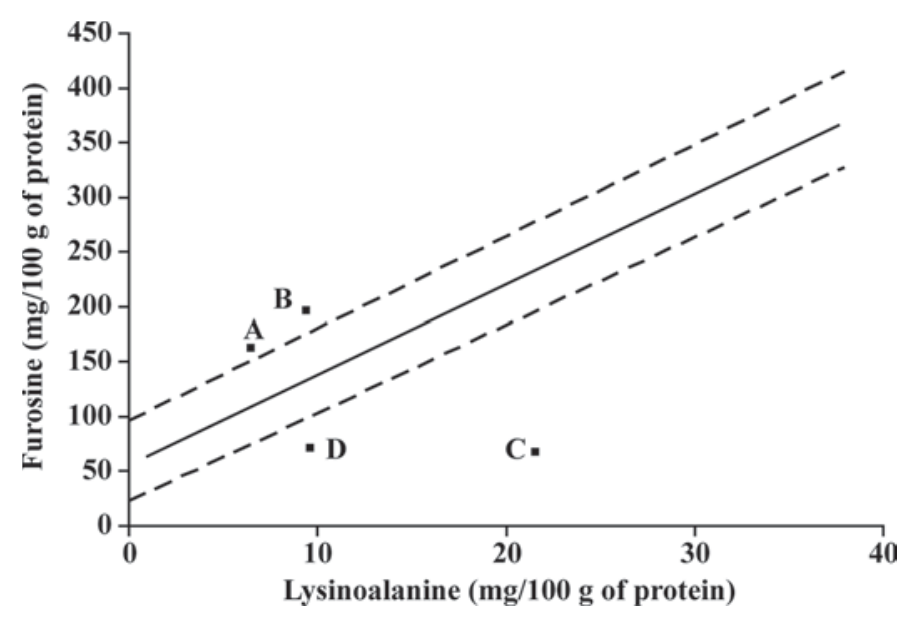

Figure 5. Correlation between furosine and lysinoalanine values in Halloumi cheeses manufactured with the addition of different amounts of calcium caseinate $(\mathrm{CaCN})$ and skim milk powder (SMP; $\mathrm{A}=5 \%$ $\mathrm{SMP} ; \mathrm{B}=5 \% \mathrm{SMP}$, prolonged cooking; $\mathrm{C}=2.5 \% \mathrm{CaCN}+2.5 \%$ $\mathrm{SMP} ; \mathrm{D}=5 \% \mathrm{CaCN})$. Prediction limits at $\pm 2 \mathrm{SD}$ and correlation line as in Figure 1. 
knowing which ingredient has been used. In the trials shown here, addition of amounts as low as $5 \%$ of these ingredients were detected by this approach but, in the case of $\mathrm{CaCN}$, lower amounts are likely detectable. The use of dried ingredients for standardization of milk for cheese manufacture offers the advantage of increasing yield at low cost, compared with using UF milk, and is therefore more likely adopted near small cheese factories producing the traditional Halloumi cheese in Cyprus. The effect of milk fortification with other commercially available milk protein products (milk protein concentrate, microparticulated whey proteins) needs to be evaluated as well.

A preliminary evaluation of genuineness of Halloumi cheese was carried out on 6 samples collected at the European market. All of them proved to be genuine.

\section{ACKNOWLEDGMENTS}

This study was financially supported by The Cyprus Milk Industry Organisation (Nicosia, Cyprus).

\section{REFERENCES}

Alichanidis, E., and A. Polychroniadou. 2008. Characteristics of major traditional regional cheese varieties of East-Mediterranean countries: A review. Dairy Sci. Technol. 88:495-510.

Calabrese, M. G., G. Mamone, S. Caira, P. Ferranti, and F. Addeo 2009. Quantitation of lysinoalanine in dairy products by liquid chromatography-mass spectrometry with selective ion monitoring. Food Chem. 116:799-805.

Cattaneo, S., F. Masotti, and L. Pellegrino. 2008. Effects of overprocessing on heat damage of UHT milk. Eur. Food Res. Technol. 226:937-948.

Cuq, J. L., and J. C. Cheftel. 1985. Lysinoalanine et aliments proteiques, Analyse, effets biologiques. Cah. Nutr. Diét. 20:373-390.

European Commission. 1998. Commission Regulation (EC) No 2527/98. OJ L317/14 26.11.98. European Commission, Brussels, Belgium.

Friedman, M. 1999. Review: Chemistry, biochemistry, nutrition and microbiology of lysinoalanine, lanthionine and histidinoalanine in food and other proteins. J. Agric. Food Chem. 47:1295-1319.

Guinee, T. P., B. T. O'Kennedy, and P. M. Kelly. 2006. Effect of milk protein standardization using different methods on the composition and yields of Cheddar cheese. J. Dairy Sci. 89:468-482.

ISO-IDF. 2004. Milk and milk products-Determination of furosine content-Ion pair reverse-phase high-performance liquid chromatography method. International Standard ISO 18329/IDF 193:2004. International Organization for Standardization, Geneva, Switzerland.

ISO-IDF. 2008. Milk and milk products-Determination of nitrogen content and crude protein calculation-Kjeldahl principle. International Standard ISO 8968/IDF 20:2008. International Organization for Standardization, Geneva, Switzerland.
Italian Legislation. 2000. Ministerial Decree 15 Dec. 2000. Ital. O.J. n. 31, 7.02.2001. Office for the Publication of Laws and Decrees, Rome, Italy.

Kelly, P. 2008. Some examples of dairy ingredient innovation and application. European Dairy Magazine 6:30-32.

Labuza, T. P., and M. Saltmarch. 1981. The nonenzymatic browning reaction as affected by water in foods. Pages 605-650 in Water Activity: Influence on Food Quality. L. B. Rockland and G. F Stewart, ed. Academic Press, New York, NY.

Lelievre, J., R. S. Shaker, and M. W. Taylor. 1990. The role of homogenization in the manufacture of halloumi and mozzarella cheese from recombined milk. J. Soc. Dairy Technol. 43:21-24.

Lelievre, J., R. S. Shaker, and M. W. Taylor. 1991. The influence of milk powder characteristics on the properties of halloumi cheese made from recombined milk. J. Soc. Dairy Technol. 44:41-44.

Masotti, F., J. A. Hogenboom, V. Rosi, I. De Noni, and L. Pellegrino. 2010. Proteolysis indices related to cheese ripening and typicalness in PDO Grana Padano cheese. Int. Dairy J. 20:352-359.

Otte, J., K. S. Larsen, and S. Bouhallab. 1998. Analysis of lactosylated $\beta$-lactoglobulin by capillary electrophoresis. Int. Dairy J. 8:857862.

Papademas, P. 1993. Halloumi cheese. Pages 117-138 in Cheese: Chemistry, Physics and Microbiology. Vol. 2. P. F. Fox, ed Chapman \& Hall, London, UK.

Papademas, P., and R. K. Robinson. 1998. Halloumi cheese: The product and its characteristics. Int. J. Dairy Technol. 51:98103.

Pellegrino, L., G. Battelli, P. Resmini, P. Ferranti, F. Barone, and F. Addeo. 1997. Effects of heat load gradient occurring in moulding on characterization and ripening of Grana Padano. Lait 77:217228.

Pellegrino, L., P. Resmini, I. De Noni, and F. Masotti. 1996. Sensitive determination of lysinoalanine for distinguishing natural from imitation Mozzarella cheese. J. Dairy Sci. 79:725-734.

Raphaelides, S. N., K. D. Antoniou, S. Vasilliadou, C. Georgaki, and A. Gravanis. 2006. Ripening effects on the rheological behaviour of Halloumi cheese. J. Food Eng. 76:321-326.

Recio, I., L. Amigo, M. Ramos, and R. Lopez-Fandino. 1997. Application of capillary electrophoresis to the study of proteolysis of caseins. J. Dairy Res. 64:221-230.

Resmini, P., and L. Pellegrino. 1991. Analysis of food heat damage by direct HPLC of furosine. Int. Chromatogr. Lab. 6:7-11.

Resmini, P., and L. Pellegrino. 1994. HPLC of furosine for evaluating Maillard reaction damage in skim milk powders during processing and storage. Pages 31-36 in Bulletin No. 298. International Dairy Federation, Brussels, Belgium.

Resmini, P., L. Pellegrino, and S. Cattaneo. 2003. Furosine and other heat-treatment indicators for detecting fraud in milk and milk products. Ital. J. Food Sci. 15:473-484.

Cyprus Standard. 1985. CYS 94:1985. Cypriot Standard Specification for fresh Halloumi. Cyprus Organisation for Standardisation, Nicosia, Cyprus.

Van Renterghem, R., and J. De Block. 1996. Furosine in consumption milk and milk powders. Int. Dairy J. 6:371-382.

Villamiel, M., M. Arias, N. Corzo, and A. Olano. 2000. Survey of the furosine content in cheeses marketed in Spain. J. Food Prot. 63:974-975

Yun, J. J., D. M. Barbano, K. L. Larose, and P. S. Kindstedt. 1998 Mozzarella cheese: Impact of nonfat dry milk fortification on composition, proteolysis, and functional properties. J. Dairy Sci. $81: 1-8$ 